\title{
Nutritional Problems in Patients with Duchenne Muscular Dystrophy
}

\author{
Hatice Tuğçe BERBEROĞLU*1 and Nilüfer ACAR-TEK ${ }^{2}$ \\ ${ }^{1}$ Research Assistant, College of Health Sciences, Department of Nutrition and Dietetics, KTO Karatay University, Turkey \\ ${ }^{2}$ Faculty of Health Sciences, Department of Nutrition and Dietetics, Gazi University, Turkey
}

*Corresponding author: Hatice Tuğçe BERBEROĞLU, Department of Nutrition and Dietetics, College of Health Sciences, KTO Karatay University, Alaaddin Kap Street, No:130, Konya, 42020, Turkey

\section{ARTICLE INFO}

Received: 崫 March 22, 2021

Published: 蔧 March 29, 2021

Citation: Hatice Tuğçe BERBEROĞLU, Nilüfer ACAR-TEK. Nutritional Problems in Patients with Duchenne Muscular Dystrophy. Biomed J Sci \& Tech Res 34(5)2021. BJSTR. MS.ID.005610.

Keywords: Nutrition; Dietary Modification; Duchenne Muscular Dystrophy; Gastrointestinal Problems; Nutritional Problems

\begin{abstract}
Duchenne muscular dystrophy (DMD) is an X-linked recessive hereditary disorder of muscles. DMD, which is a multisystemic disease, patients often experience gastrointestinal problems such as gastroesophageal reflux, constipation, dysphagia, delayed gastric motility, dental and jaw structure disorders and chewing disorders, in addition to musculoskeletal, pulmonary and heart problems. These problems, which increase with age, increase the risk of developing obesity and malnutrition and worsen the disease progression. This decreases the quality of life of patients and those who care for patients. There is no definite treatment for DMD disease. In addition to medical treatment, nutritional regulations ensure that patients receive enough daily energy, protein, various micronutrients and fluid, protect patients from obesity and malnutrition, and make dietary modifications in line with the presence of nutritional and gastrointestinal problems is important. Dietary modifications such as changing the texture of foods, dividing the foods into small pieces, choosing foods with high energy content or more liquid foods should be considered as needed. If necessary, gastrostomy or enteral feeding options should also be considered. Although there are data on the benefits of dietary supplements, information on the use of these products in individuals with DMD is limited. In this review, common nutritional problems in patients with DMD, dietary modifications related to the management of these problems and nutritional therapy will be evaluated.
\end{abstract}

\section{Introduction}

Duchenne muscular dystrophy (DMD) is an X-linked recessive hereditary disorder resulting from a mutation located on chromosome Xp21 in the dystrophin gene [1-3]. DMD, affecting 1 in 3500 males, [4] is the most common congenital muscle dystrophy $[4,5]$. DMD is a genetic degenerative disease characterised by decreased muscle mass and function $[2,6]$. This degeneration starts from birth; [7] resulted pulmonary, cardiovascular, orthopaedic and nutritional complications affect the skeletal, cardiac and smooth $[8,9]$. Therefore, multidisciplinary clinics involving cardiologists, neurologists, dieticians, nurses, physiotherapists, geneticists, pulmologists and primary care physicians are very crucial in diagnosing and preventing the complications and managing the progression of DMD [9-11]. Gastrointestinal disorders such as constipation, delayed gastric emptying, gastroesophageal reflux, and problems with chewing and swallowing are frequently seen in DMD [9,12-14]. Nutrition therapy and dietary modifications ameliorate disease progression by decreasing complications $[13,14]$. In this review, we will assess the nutritional problems frequently seen in patients with DMD, dietary modifications related to the management of these problems and nutrition therapy.

\section{Duchenne Muscular Dystrophy and Nutritional Problems}

Gastrointestinal and nutritional complications, which are common in neuromuscular diseases, $[12,13]$ increase with age [12]. Increased or decreased body weight, mandibular contracture, [15] gastroesophageal reflux, [9,13] delayed gastric emptying, constipation, [9] chewing disorders, choking episodes, [9,13] 
heartburn, [13] difficulties in bringing food to mouth $[13,14,16]$ and dysphagia [9] are common gastrointestinal and nutritional complications of patients with DMD. In a study conducted in 2006, 55 of 118 (47\%) patients with DMD between the age of 3 and 35 years had gastrointestinal problems [13]. Esophageal dysmotility, delayed gastric emptying, glucocorticoid treatment and scoliosis are risk factors for developing gastroesophageal reflux in patients with DMD [11,17]. Skeletal muscle weakness leads to delayed gastric emptying $[11,17]$ which causes postprandial abdominal pain, nausea, vomiting, early saturation and decreased appetite in patients with DMD [11]. Constipation caused by weakening of abdominal walls and intestinal muscles leads to dehydration, which is one of the most common gastrointestinal complications of DMD and usually occurs in individuals in their 20s and increases with age [18]. In a study conducted by Pane, et al. [13] it was shown that constipation was developed in $36 \%$ of patients with DMD and was seen more frequently in patients after 18 years of age. In the study by Gottrand and Guillonneau [19] constipation was observed in 9 out of 12 patients with DMD. Factors such as colon muscle involvement, physical inactivity, weakening of abdominal wall muscles, insufficient fluid consumption and decreased colonic transit time aggravate constipation [11] and lead to reduced appetite and food consumption [9].

In addition to constipation, gastrointestinal dilatation has been reported in patients who swallow air during ventilator use [20]. During chewing and swallowing, poor head control [21] and hypertrophic tongue muscles cause dental health problems and lead to a decrease in quality of life [22]. Hypertrophic tongue muscles combined with weakening of the orofacial muscles cause changes in facial morphology, where patients have large dental arches that cause malocclusions $[18,23,24]$. This prevents contact between the upper and lower molars preventing chewing [18]. This leads to longer eating times and an increased risk of choking $[9,13,25]$. Lastly, neglecting dental hygiene leads to tooth decay and tooth loss, worsening eating disorder [18]. Patients with DMD are at an increased risk of obesity in the early stages of life and malnutrition in adulthood $[9,11,26]$. It has been shown that approximately $54 \%$ of individuals with DMD between the ages of 10 and 13 years have malnutrition or overfeeding problems [27]. In the early stages of the disease, obesity is frequently seen because of decreased physical activity, [11] metabolic changes 18 and corticosteroid use $[11,12,18,28,29]$. As a result of weakness in the oropharyngeal muscles, patients have difficulty in swallowing and locomotor insufficiency, which reduces food intake [5,14]. As a precaution, overfeeding of patients is ineffective in increasing muscle protein synthesis; in addition, it induces the development of obesity in patients [5].

Obesity increases the risk of glucose intolerance and promotes disease progression by increasing the burden on weakened muscles [18,30]. Other complications of obesity include insulin resistance, dyslipidemia, hypertension, obstructive sleep apnoea, $[9,31]$ impaired pulmonary and cardiac functions $[9,12,16]$ and hypercapnia caused by increased carbon dioxide production as a result of excessive nutrition $[5,32,33]$. Due to decreased appetite, difficulty in swallowing and chewing and digestive problems, the patients are at risk of malnutrition, [18] increased muscle loss, [5,34] pressure sores and decreased immunity [5,35,36]. Therefore, considering all these problems, complications caused by malnutrition reduce the quality of life of patients with DMD and the caregivers $[8,12,18,21]$.

\section{Management of Nutritional Problems}

In recent years, there has been an increase in studies on nutritional difficulties in patients with DMD, demonstrating an increased interest in the assessment and management of nutritional problems of individuals with neuromuscular diseases [9,1113,16,20,21,37]. A multidisciplinary approach, which includes dieticians, speech therapists, neurologists and pneumologists, is required for the management of eating disorders in patients $[13,16]$. Regular assessment of dysphagia is very important. It is important to examine if there are difficulties in swallowing food, if food is adhering to the throat; it is also important to assess the average time to eat and the effects of food on quality of life [11,38]. In patients with dysphagia that do not aspirate, it is beneficial to divide food it into small pieces $[13,16,18]$ or provide liquid foods $[13,18]$. In addition, water consumption during and after meals has been shown to reduce swallowing problems and remove oropharyngeal food residues [21]. Thickening agents have also been used for many years to prevent dysphagia in patients with swallowing difficulties [37]. However, previous studies have shown that these thickeners are not suitable for patients with DMD and other neuromuscular diseases $[37,39]$ because thickened liquid and solid foods increase oral phase problems and pharyngeal residue accumulation [37]. Food texture is classified by 4 main categories of viscosity which can be altered to facilitate swallowing. Table 1 shows dysphagia diet and sample foods at all levels [9,40].

Table 1: Dysphagia Diet.

\begin{tabular}{|c|c|c|}
\hline Level 1 & $\begin{array}{c}\text { Description of Texture } \\
\text { throughout, requires no } \\
\text { chewing }\end{array}$ & $\begin{array}{c}\text { Examples of Foods } 1 \text { and 2 baby foods, } \\
\text { applesauce, yogurt without } \\
\text { pieces of fruit }\end{array}$ \\
\hline Level 2 & $\begin{array}{c}\text { Mechanical altered, requires } \\
\text { some chewing }\end{array}$ & $\begin{array}{c}\text { Oatmeal, mashed potatoes, } \\
\text { banana, refried beans, canned } \\
\text { fruits and tender-cooked } \\
\text { vegetables }\end{array}$ \\
\hline Level 3 & $\begin{array}{c}\text { Soft foods, requires more } \\
\text { chewing }\end{array}$ & $\begin{array}{c}\text { Chopped meats and fish, } \\
\text { breads, most fruits without } \\
\text { skins or seeds }\end{array}$ \\
\hline Regular & Chewing likely required & All foods allowed \\
\hline
\end{tabular}


In patients with severe swallowing disorders or decreased body weight as a result of malnutrition, a gastrostomy tube and surgical intervention should be considered [13,18,37]. In case of aspiration, percutaneous endoscopic gastrostomy should be considered with the complete prohibition of oral food intake [37]. At the same time, the presence of malocclusion or macroglossi or both, which are frequently seen in patients with DMD, should not be ignored $[37,41,42]$ because these problems reduce tongue movement and affect the passage of food into the pharynx [37,43]. Dietary modifications should be made according to tongue pressure levels of patients. For example, patients with low tongue pressure should eat a less solid diet $[37,44]$. In addition, it is recommended to consume frequent and small amounts of energy-dense food to reduce the time and effort spent on eating. Lastly, it is recommended to rinse the throat with water after each meal $[37,45]$. Delayed gastric emptying in DMD patients is significantly increased compared with that in healthy individuals; it worsens with the progression of the disease [46]. Delayed gastric emptying slows down access of nutrients to the small intestine causing malnutrition $[9,46]$. Gastroesophageal reflux increases the risk of aspiration [12]. Appropriate treatment options include dietary modification, pharmacological treatment and post-pyloric feeding via a gastrojejunal feeding tube [11].

Gastroesophageal reflux is another gastrointestinal problem of patients with DMD. It is recommended that individuals with reflux symptoms consume less food but more frequently [11]. Treatment of constipation is particularly important in malnourished patients [9]. Nutrition and drug therapy should be applied according to the causes and severity of constipation in these individuals [9,47]. Complementary and alternative medicines are often used to ameliorate symptoms in these individuals. Although these types of treatments have been beneficial in some cases, further research is needed to confirm their safety and efficacy [9]. Adequate fluid and fibre consumption can prevent or treat constipation [12]. Fibre requirements of males at the age of 4-8, 9-13 and 14-18 are 25 g/day, $31 \mathrm{~g} /$ day and $38 \mathrm{~g} /$ day, respectively [9]. To prevent dental health problems, the patients should avoid excessive consumption of sugary or acidic food and beverages and brush their teeth regularly [18]. Although nutritional complications are common in individuals with DMD, they are directly linked to the progression of the disease and quality of life. To improve the quality of life of these patients, a multidisciplinary treatment approach is needed that combines understanding the factors that adversely affect the nutritional status of the patient, anthropometric measurements and dietary modifications.

\section{Nutritional Approach in Duchenne Muscular Dystrophy}

Nutritional imbalances of individuals with DMD adversely affect respiratory, skeletal muscle and cardiac systems [11]. However, an appropriate nutrition programme can improve the quality of life of patients with diagnosed with neuromuscular disease and their family members [20]. The aim of nutritional therapy is to prevent obesity and malnutrition by evaluating body weight and height regularly [11]. As the disease progresses, a dietician should be consulted to prevent obesity and malnutrition and to administer drug or non-drug treatments by monitoring nutrition and the gastrointestinal system [20]. Because there are no recommendations for daily energy and protein intakes for individuals with DMD, there is a need to develop nutritional guidelines according to the different needs of patients at different stages of the disease. For this purpose, studies involving metabolic results of distropatology and disease progression are needed that can clearly explain the effect of changing energy and nutrient requirements [48]. If patients unintentionally lose $>10 \%$ of their body weight in 1 year, it is recommended to increase nutrients and energies [37]. It is very important for individuals with DMD to ensure adequate intake of protein, calcium, vitamin D and fluids and both soluble and insoluble forms of fibre [49,50]. In a review published in 2018 by Birnkrant et al., it was shown that $45-65 \%$ of total energy intake should be obtained from carbohydrates, 20$35 \%$ from fats and $10-35 \%$ from proteins. Acceptable ranges for children and adolescents are similar to adults $[11,51]$.

\section{Protein Requirement}

Although there is very little data in the literature about the amount of protein that individuals should consume, the minimum amount of protein to be taken should be adjusted according to DRI recommendations for age. It is recommended that $10 \%-30 \%$ of total energy consumed in individuals between the ages of 4-18 years come from protein [9,52]. Table 2 summarizes energy and protein intake recommendations for each age group [9]. It has been reported that individuals of age 4-13, 14-18 and 19 years should consume $0.95,0.85$ and $0.80 \mathrm{~g} / \mathrm{kg}$ weight/day protein, respectively [11]. The effects of this amount on disease pathology in mouse models are shown to be uncertain [53,54]. Some studies report that high protein diets do not have any positive effect [18]. Limited findings on the positive effects of additional protein intake on the disease suggest that additional protein intake is not necessary in these patients $[9,12,53]$. 
Table 2: Estimated Energy and Protein Requirements for Males 3-18 Years.

\begin{tabular}{|c|c|c|c|c|c|}
\hline \multicolumn{4}{|c|}{ Dietary Referance Intake-Energy } & \multicolumn{2}{|c|}{ Dietary Referance Intake-Protein } \\
\hline Age (Years) & $\begin{array}{l}\text { Basal Metabolic Rate } \\
\text { (kcal/kg/d) }\end{array}$ & $\mathrm{kcal} / \mathrm{d}$ & $\mathrm{kcal} / \mathrm{kg} / \mathrm{d}$ & $g / d$ & $\mathrm{~g} / \mathrm{kg} /$ day \\
\hline 3 & 57 & 1020 & 85 & 13 & 1,08 \\
\hline $4-5$ & 48 & 1402 & 70 & 19 & 0,95 \\
\hline $6-7$ & 48 & 1279 & 64 & 19 & 0,95 \\
\hline 8 & 48 & 1186 & 59 & 19 & 0,95 \\
\hline $9-11$ & 36 & 1756 & 49 & 34 & 0,94 \\
\hline $12-13$ & 36 & 1599 & 44 & 34 & 0,94 \\
\hline $14-16$ & 28 & 2385 & 39 & 52 & 0,85 \\
\hline $17-18$ & 28 & 2230 & 37 & 52 & 0,85 \\
\hline$>18$ & 28 & 2550 & 36 & 56 & 0,80 \\
\hline
\end{tabular}

\section{Micronutrients}

Although little is known about the daily micronutrient requirements for patients with DMD, it is known that vitamin $\mathrm{D}$ and calcium are the most important nutrients during corticosteroid treatment in patients [16]. Canalis, et al. [55] reported that glucocorticoids cause osteoporosis by suppressing bone formation and increasing bone resorption. Decreased physical activity has a negative effect on bone health, increasing the risk of fractures in these individuals [56]. In a case-control study by Söderpalm et al. [56] serum $25(\mathrm{OH}) \mathrm{D}$ vitamin levels were compared in 24 patients with DMD and 24 healthy individuals, most of whom received prednisoneol treatment. It was shown that serum vitamin D levels, bone mineral density and bone turnover were significantly lower in DMD patients compared with healthy subjects even though food consumption records showed that they both received sufficient amounts of vitamin D and calcium. Therefore, it is thought that either the vitamin $\mathrm{D}$ and calcium requirements for individuals diagnosed with DMD should be increased or there is a different mechanism that causes vitamin D deficiency in DMD patients. Recent studies have shown that children with DMD may have low serum 25 $(\mathrm{OH}) \mathrm{D}$ levels and poor bone health at the time of diagnosis, even before initiating steroid therapy $[57,58]$. In addition, increased bone turnover and decreased serum $25(\mathrm{OH})$ D levels were found in DMD patients with or without steroid treatment. 29 In a study by Biggar, et al. [59] patients receiving corticosteroid therapy were recommended to receive $750 \mathrm{mg}$ calcium and $1000 \mathrm{mg}$ IU vitamin D supplementation. In another study, it was emphasised that elemental calcium intake should vary with age: $1000 \mathrm{mg} /$ day between 4-8 years, $1300 \mathrm{mg} /$ day between 9-18 years and 1000 $\mathrm{mg} /$ day after 18 years [60]. In addition to consuming foods rich in calcium and vitamin D, nutritional supplements can also be used to ensure adequate calcium and vitamin D intake [9]. However, there is little data in the literature about which type and what doses should be consumed [18].

\section{Fluid Requirement}

There is limited information in the literature about the amount of fluid consumed by individuals with neuromuscular disease; however, adequate fluid consumption is recommended to help prevent constipation [12]. Fluid requirements of individuals vary with physical activity, age and weather, but patients are recommended to take $2 \mathrm{~L}$ of fluid daily [49]. In a review, it is reported that the recommended fluid consumption may vary according to body weight in addition to age. It is recommended to intake $1.2 \mathrm{~L}$ between ages $4-8$ years, $1.8 \mathrm{~L}$ between ages 9-13 years, 2.6 $\mathrm{L}$ between ages 14-18 years and 3.0 L for those older than 19 years old. 11 The Holliday-Segar method, which determines fluid requirement based on body weight, is shown in Table $3[11,61]$.

Table 3: Holliday-Segar Method.

\begin{tabular}{|c|c|}
\hline Body Weight (kg) & Fluid Requirement \\
\hline $1-10$ & $100 \mathrm{~mL} / \mathrm{kg}$ \\
\hline $11-20$ & $1000 \mathrm{~mL}+50 \mathrm{~mL}$ for each $\mathrm{kg}$ over $10 \mathrm{~kg}$ \\
\hline$>20$ & $1500 \mathrm{~mL}+20 \mathrm{~mL}$ for each $\mathrm{kg}$ over $20 \mathrm{~kg}$ \\
\hline
\end{tabular}

\section{Various Nutritional Supplements}

It is estimated that the use of alternative and complementary medicine such as nutritional supplements for the management of chronic diseases worldwide varies between $6 \%$ and $65 \%$ in adults [62]. There are also studies showing the use of these nutritional supplements by paediatric populations who have chronic disease or disability $[63,64]$. In two Canadian studies, the frequency of use of alternative and complementary medicine in the paediatric population with neuromuscular disease and DMD were reported to be $30 \%$ [65] and $20 \%$, [66] respectively. The results of the meta-analysis of Nabukera, et al. [67] showed that the use of these supplements is quite common in patients with DMD and Becker Muscular Dystrophy. So far; studies have been conducted investigating the effects of many different nutrients on 
the progression of the disease. These include n-3 fatty acids, [68] leucine, [69] vitamin D[29] L-carnitine, [70] Coenzyme Q10, [71] taurine, [72] green tea extract, [73] curcumin [74] and resveratrol [75]. However, data on the benefits of nutritional supplements are limited and contradictory. In addition, there are no standardised guidelines for the doses of these nutritional supplements. [18]. Although nutritional supplements may have potential positive effects, they can be harmful if taken at high doses or with other drugs because there is a possibility for drug interaction[18]

\section{Conclusion}

DMDis a multisystemic disease that progresses with the catabolic processes of the body and causes skeletal, cardiac, pulmonary, gastrointestinal system and nutritional problems. These problems include obesity, malnutrition, chewing and swallowing disorders, tooth and jaw structure disorders, constipation, delayed gastric mobility and gastroesophageal reflux. These problems significantly decrease the quality of life in these patients by deteriorating their nutritional status and causing the disease progression. Recent studies have emphasised the need to adopt a multidisciplinary approach in the management of nutritional difficulties and gastrointestinal problems that involves speech therapists, dieticians, neurologists and pneumologists. Anthropometric measurements and body composition should be evaluated regularly in these patients to determine their required energy intake. In addition, dietary modifications should be considered such as changing the food texture, dividing the foods into small pieces, preferring foods with high energy content or consuming more fluids. Additionally, when necessary, the use of gastrostomy tube or enteral nutrition products should be considered. Although nutritional supplements may provide some benefit, there is limited information on the effective use of nutritional supplements for patients with DMD, which warrants further studies. In summary, it is expected that proper patient evaluation and adoption of a tailored approach will improve the quality of life of patients and their caregivers.

\section{Contributors}

Both authors wrote sections, controlled English grammer, spelling, approved the final manuscript and followed journal guidelines.

\section{Disclosure Statement}

No potential conflict of interest was reported by the authors.

\section{References}

1. Davoodi J, Markert C, Voelker K, Hutson S, Grange R (2012) Nutrition Strategies to Improve Physical Capabilities in Duchenne Muscular Dystrophy. Phys Med Rehabil Clin N Am 23(1): 1-16.

2. Shimizu-Fujiwara M, Komaki H, Nakagawa E, Yasushi Oya, Toshiyuki Fujisaki, et al. (2012) Decreased resting energy expenditure in patients with Duchenne muscular dystrophy. Brain and Development 34(3): 206212.
3. Gürsoy S, Erçal MD (2016) Duchenne Musküler Distrofi Tedavisindeki Stratejiler. Türkiye Klinikleri Pediatrik Bilimler - Özel Konular 12(4): 6066.

4. Emery AEH, Eh E (1991) Population Frequences of Inherited Neuromuscular Diseases-A World Survey. Neuromuscular Disorders I(I): 19-29.

5. Gonzalez-Bermejo J, Lofaso F, Falaize L, M Lejaille, JC Raphaël, et al. (2005) Resting energy expenditure in Duchenne patients using home mechanical ventilation. European Respiratory Journal 25(4): 682-687.

6. Mok E, Daubrosse C, Hankard R, Christel Daubrosse, Jean-Eudes Fontan, et al. (2006) Estimating body composition in children with Duchenne muscular dystrophy: Comparison of bioelectrical impedance analysis and skinfold-thickness measurement. American Journal of Clinical Nutrition 83(1): 65-69.

7. Emery AEH (2002) The muscular dystrophies. Lancet (London, England) 359(9307): 687-695.

8. Liew WKM, Kang PB (2013) Recent developments in the treatment of Duchenne muscular dystrophy and spinal muscular atrophy. Therapeutic Advances in Neurological Disorders 6(3): 147-160.

9. Davis J, Samuels E, Mullins L (2015) Nutrition Considerations in Duchenne Muscular Dystrophy. Nutrition in Clinical Practice 30(4): 511521.

10. Bushby K, Bourke J, Bullock R, Eagle M, Gibson M, et al. (2005) The multidisciplinary management of Duchenne muscular dystrophy. Current Paediatrics 15(4): 292-300.

11. Birnkrant DJ, Bushby K, Muscular JW, Susan D Apkon, Angela Blackwell, et al. (2018) Diagnosis and management of Duchenne muscular dystrophy, part 1: diagnosis, and neuromuscular, rehabilitation, endocrine, and gastrointestinal and nutritional management HHS Public Access. Lancet Neurol 17(3): 251-267.

12. Salera S, Menni F, Moggio M, Guez S, Sciacco M, et al. (2017) Nutritional challenges in duchenne muscular dystrophy. Nutrients 9(6).

13. Pane M, Vasta I, Messina S, Domenica Sorleti, Annie Aloysius, et al. (2006) Feeding problems and weight gain in Duchenne muscular dystrophy. European Journal of Paediatric Neurology 10(5-6): 231-236.

14. Willig TN, Paulus J, Lacau Saint^^uily J, Béon C, Navarro J (1994) Swallowing problems in neuromuscular disorders. Archives of Physical Medicine and Rehabilitation 75(11): 1175-1181.

15. Van Bruggen HW, Van Den Engel-Hoek L, Steenks MH, EM Bronkhorst, NHJ Creugers, et al. (2015) Reduced mandibular range of motion in Duchenne muscular dystrophy: Predictive factors. Journal of Oral Rehabilitation 42(6): 430-438.

16. Davidson ZE, Truby H (2009) A review of nutrition in Duchenne muscular dystrophy. Journal of Human Nutrition and Dietetics 22(5): 383-393.

17. Borrelli O, Salvia G, Mancini V, Lucio Santoro, Francesca Tagliente, et al. (2005) Evolution of Gastric Electrical Features and Gastric Emptying in Children with Duchenne and Becker Muscular Dystrophy. The American Journal of Gastroenterology 100(3): 695-702.

18. Verhaart IEC, Van den Engel-Hoek L, Fiorotto ML, Franken-Verbeek M, Vroom E (2018) Nutrition in Duchenne muscular dystrophy 16-18 March 2018, Zaandam, the Netherlands. Neuromuscular Disorders 28(8): 680-689.

19. Gottrand F, Guillonneau I (1991) Segmental Colonic Transit Time in Duchenne Muscular Dystrophy. Archives of Disease in Childhood 66(10): 1262.

20. Bushby K, Finkel R, Birnkrant DJ, Laura E Case, Paula R Clemens, et al. (2010) Diagnosis and management of Duchenne muscular dystrophy, part 2: implementation of multidisciplinary care. Diabetol Metab Syndr 9(2): 177-189. 
21. Van den Engel-Hoek L, De Groot IJM, De Swart BJM, Erasmus CE (2015) Feeding and Swallowing Disorders in Pediatric Neuromuscular Diseases: An Overview. Journal of Neuromuscular Diseases 2(4): 357-369.

22. Jones K, Pitceathly RD, Rose MR, Susan McGowan, Marguerite Hill, et al. (2016) Interventions for dysphagia in long-term, progressive muscle disease. Cochrane Database of Systematic Reviews (2).

23. Egli F, Botteron S, Morel C, Kiliaridis S (2018) Growing patients with Duchenne muscular dystrophy: longitudinal changes in their dentofacial morphology and orofacial functional capacities 40(2): 140-148.

24. Eckardt L, Harzer W (1996) Facial structure and functional findings in patients with progressive muscular dystrophy (Duchenne). American journal of orthodontics and dentofacial orthopedics: official publication of the American Association of Orthodontists, its constituent societies, and the American Board of Orthodontics 110(2): 185-190.

25. Aloysius A, Born P, Kinali M, Davis T, Pane M, et al. (2008) Swallowing difficulties in Duchenne muscular dystrophy: Indications for feeding assessment and outcome of videofluroscopic swallow studies. European Journal of Paediatric Neurology 12(3): 239-245.

26. Martigne L, Salleron J, Le Mayer M, Jean-Marie Cuisset, Alain Carpentier, et al. (2019) Natural evolution of weight status in Duchenne muscular dystrophy: a retrospective audit. British Journal of Nutrition 105: 14861491.

27. Willig TN, Carlier L, Legrand M, Rivière H, Navarro J (1993) Nutritional assessment in Duchenne muscular dystrophy. Developmental medicine and child neurology 35(12): 1074-1082.

28. Elliott SA, Davidson ZE, Davies PSW, Truby H (2015) A bedside measure of body composition in Duchenne muscular dystrophy. Pediatric Neurology 52(1): 82-87.

29. Bianchi ML, Biggar D, Bushby K, Rogol AD, Rutter MM, et al. (2011) Endocrine Aspects of Duchenne Muscular Dystrophy. Neuromuscular Disorders 21(4): 298-303.

30. Saure C, Caminiti C, Weglinski J, De Castro Perez F, Monges S (2018) Energy expenditure, body composition, and prevalence of metabolic disorders in patients with Duchenne muscular dystrophy. Diabetes and Metabolic Syndrome: Clinical Research and Reviews 12(2): 81-85.

31. Dietz WH (1998) Health consequences of obesity in youth: Childhood predictors of adult disease. Pediatrics 101(3 Pt II): 518-525.

32. Aldrich TK (1993) Nutritional factors in the pathogenesis and therapy of respiratory insufficiency in neuromuscular diseases. Monaldi archives for chest disease 48(4): 327-330.

33. Matsumura T, Saito T, Miyai I, Nozaki S, Kang J (1998) Excess caloric intake induced severe hypercapnia in a patient with Duchenne muscular dystrophy on noninvansive positive pressure ventilation. Rinsho shinkeigaku = Clinical neurology 38(9): 822-825.

34. McLoughlin DM, Wassif WS, Morton J, Spargo E, Peters TJ, et al. (2000) Metabolic abnormalities associated with skeletal myopathy in severe anorexia nervosa. Nutrition 16(3): 192-196.

35. McMurray DN, Watson RR, Reyes MA (1981) Effect of renutrition on humoral and cell-mediated immunity in severely malnourished children. The American Journal of Clinical Nutrition 34(10): 2117-2126.

36. Keusch GT (2003) The History of Nutrition: Malnutrition, Infection and Immunity. The Journal of Nutrition 133(1): 336-340.

37. Toussaint M, Davidson Z, Bouvoie V, Evenepoel N, Haan J, et al. (2016) Dysphagia in Duchenne muscular dystrophy: practical recommendations to guide management. Disability and Rehabilitation 38(20): 2052-2062.

38. Archer SK, Garrod R, Hart N, Miller S (2013) Dysphagia in Duchenne muscular dystrophy assessed by validated questionnaire. International Journal of Language and Communication Disorders 48(2): 240-246.

39. Van den Engel-Hoek L, Erasmus CE, Van Hulst KCM, Arvedson JC, De Groot IJM, et al. (2014) Children with Central and Peripheral Neurologic Disorders Have Distinguishable Patterns of Dysphagia on
Videofluoroscopic Swallow Study. Journal of Child Neurology 29(5): 646-653.

40. (2002) National Dysphagia Diet Task Force. American Dietetic Association. National Dysphagia Diet: Standardization for Optimal Care. American Dietetic Association.

41. Ghafari J, Clark RE, Shofer FS, Berman PH (1988) Dental and occlusal characteristics of children with neuromuscular disease. American Journal of Orthodontics and Dentofacial Orthopedics 93(2): 126-132.

42. Verdebout CM, Botteron S, Kiliridis S (2007) Dentofacial Characacteristics of Growing Patients with Duchenne Muscular Dystrophy: A Morphological Study. European Journal of Orthodontics 29(5): 500-507.

43. Nozaki S, Umaki Y, Sugishita S, Tatara K, Adachi K, et al. (2007) Videofluorographic assessment of swallowing function in patients with Duchenne muscular dystrophy. Rinsho shinkeigaku 47(7): 407-412.

44. Umemoto G, Furuya H, Kitashima A, Sakai M, Arahata H, et al. Dysphagia in duchenne muscular dystrophy versus myotonic dystrophy type 1 . Muscle and Nerve 46(4): 490-495.

45. Van Den Engel-Hoek L, Erasmus CE, Hendriks JCM, Alexander CH Geurts, Willemijn M Klein, et al. (2013) Oral muscles are progressively affected in Duchenne muscular dystrophy: Implications for dysphagia treatment. Journal of Neurology 260(5): 1295-1303.

46. Borrelli O, Salvia G, Mancini V, Lucio Santoro, Francesca Tagliente, et al. (2005) Evolution of gastric electrical features and gastric emptying in children with Duchenne and Becker muscular dystrophy. The American journal of gastroenterology 100(3): 695-702.

47. Weber TK, Toporovski MS, Tahan S, Neufeld CB, De Morais MB (2014) Dietary fiber mixture in pediatric patients with controlled chronic constipation. Journal of Pediatric Gastroenterology and Nutrition 58(3): 297-302.

48. Radley-Crabb HG, Marini JC, Sosa HA, Castillo LI, Grounds MD, et al. (2014) Dystropathology increases energy expenditure and protein turnover in the Mdx mouse model of Duchenne muscular dystrophy. PLoS ONE 9(2).

49. Davidson ZE, Rodden G, Mazala D, Cynthia Moore (2016) Practical Nutrition Guidelines for Individuals with Duchenne Muscular Dystrophy.

50. (2005) Dietary Reference Intakes for Energy, Carbohydrate, Fiber, Fat, Fatty Acids, Cholesterol, Protein, and Amino Acids (Macronutrients) National Academies Press, Washington, DC. USA.

51. (2006) Academies I of M of the N. Part 1: Development and Application. In: Otten J, Hellwig JP, Meyers LD (Eds.)., Dietary Reference Intakes. Essential Guide to Nutrient Requirement. The National Academies Press, Washington DC, USA, pp. 3-19.

52. Larson TA (2013) Pocket Guide to Children with Special Health Care and Nutritional Needs. Journal of Nutrition Education and Behavior 45(1): 94. e5.

53. Verhaart IEC, Van de Vijver D, Boertje-Van der Meulen JW, Kayleigh Putker, Kevin Adamzek, et al. (2019) A modified diet does not ameliorate muscle pathology in a mouse model for Duchenne muscular dystrophy. PLoS ONE 14(4).

54. Radley-Crabb HG, Fiorotto ML, Grounds MD (2011) The different impact of a high fat diet on dystrophic mdx and control C57Bl/10 mice. PLoS currents 3 .

55. Canalis E, Bilezikian JP, Angeli A, Giustina A (2004) Perspectives on glucocorticoid-induced osteoporosis. Bone 34(4): 593-598.

56. Söderpalm AC, Magnusson P, Åhlander AC, Jón Karlsson, Anna-Karin Kroksmark, et al. (2007) Low bone mineral density and decreased bone turnover in Duchenne muscular dystrophy. Neuromuscular Disorders 17(11-12): 919-928.

57. Angelini C, Peterle E (2012) Old and new therapeutic developments in steroid treatment in Duchenne muscular dystrophy. Acta Myologica 31(1): 9-15. 
58. Bianchi ML, Mazzanti A, Galbiati E, S Saraifoger, A Dubini, et al. (2003) Bone mineral density and bone metabolism in Duchenne muscular dystrophy. Osteoporosis International 14(9): 761-767.

59. Biggar WD, Harris VA, Eliasoph L, Alman B (2006) Long-term benefits of deflazacort treatment for boys with Duchenne muscular dystrophy in their second decade. Neuromuscular Disorders 16(4): 249-255.

60. (2020) Calcium - Health Professional Fact Sheet.

61. Holliday M, Segar W (1998) The Maintenance Need for Water in Parenteral Fluid Therapy. Paediatric Anaesthesia 1957(19): 823-832.

62. Ernst E (2000) Complementary and alternative medicine in rheumatology. Best Practice and Research: Clinical Rheumatology 14(4): 731-749.

63. Sanders H, Davis MF, Duncan B, Meaney FJ, Haynes J, et al. (2003) Use of Complementary and Alternative Medical Therapies Among Children with Special Health Care Needs in Southern Arizona. Pediatrics 111(3): 584-587.

64. Molassiotis A, Cubbin D (2004) "Thinking outside the box": Complementary and alternative therapies use in paediatric oncology patients. European Journal of Oncology Nursing 8(1): 50-60.

65. Soo I, Mah JK, Barlow K, Hamiwka L, Wirrell E (2005) Use of complementary and alternative medical therapies in a pediatric neurology clinic. Canadian Journal of Neurological Sciences 32(4): 524 528.

66. Samdup DZ, Smith RG, Il Song S (2006) The use of complementary and alternative medicine in children with chronic medical conditions. American Journal of Physical Medicine and Rehabilitation 85(10): 842846.

67. Nabukera S, Romitti P, Campbell K (2015) Use of Complementary and Alternative Medicine by Males with Duchenne or Becker Muscular Dystrophy. Mol Psychiatry 20(6): 1588-1595.

\section{ISSN: 2574-1241}

DOI: 10.26717/BJSTR.2021.34.005610

Hatice Tuğçe BERBEROĞLU. Biomed J Sci \& Tech Res

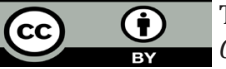

This work is licensed under Creative Commons Attribution 4.0 License

Submission Link: https://biomedres.us/submit-manuscript.php
68. Rodríguez-Cruz M, Cruz-Guzmán O del R, Almeida-Becerril T, Alan Donovan Solís-Serna, Salvador Atilano-Miguel, et al. (2018) Potential therapeutic impact of omega-3 long chain-polyunsaturated fatty acids on inflammation markers in Duchenne muscular dystrophy: A doubleblind, controlled randomized trial. Clinical Nutrition 37(6): 1840-1851.

69. Banfi S, D’Antona G, Ruocco C, Mirella Meregalli, Marzia Belicchi, et al. (2018) Supplementation with a selective amino acid formula ameliorates muscular dystrophy in mdx mice. Scientific Reports: 8(1).

70. Oh J, Kang H, KİM H, Lee J, CHOİ K, et al. (2005) The Effect of L-Carnitin Supplementation on the Dystrophic Muscle and Exercise Tolerance of Muscular Dystrophy (mdx) Mice. Journal of the Korean Neurological Association 23(4): 519-527.

71. Spurney CF, Rocha CT, Henricson E, Julaine Florence, Jill Mayhew, et al. (2011) CINRG pilot trial of coenzyme Q10 in Steroid-Treated duchenne muscular dystrophy. Muscle Nerve 44(2): 174-178.

72. Cozzoli A, Rolland JF, Capogrosso RF, V T Sblendorio, V Longo, et al. (2011) Evaluation of potential synergistic action of a combined treatment with alpha-methylprednisolone and taurine on the mdx mouse model of Duchenne muscular dystrophy. Neuropathology and Applied Neurobiology 37(3): 243-256.

73. Evans NP, Call JA, Bassaganya-Riera J, Robertson JL, Grange RW (2010) Green tea extract decreases muscle pathology and NF- $\kappa B$ immunostaining in regenerating muscle fibers of $\mathrm{mdx}$ mice. Clinical Nutrition 29(3): 391-398.

74. Pan Y, Chen C, Shen Y, Chun-Hua Zhu, Gang Wang, et al. (2008) Curcumin alleviates dystrophic muscle pathology in mdx mice. Molecules and cells 25(4): 531-537.

75. Hori YS, Kuno A, Hosoda R, Masaya Tanno, Tetsuji Miura, et al. (2011) Resveratrol Ameliorates Muscular Pathology in the Dystrophic mdx Mouse, a Model for Duchenne Muscular Dystrophy. Journal of Pharmacology and Experimental Therapeutics 338(3): 784-794.

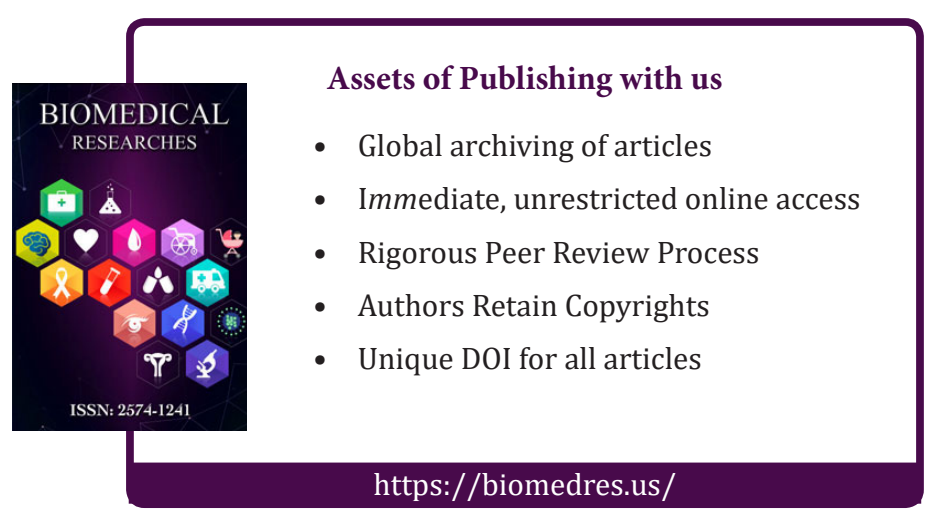

